\title{
Biologia floral de cinco espécies de Passiflora L. (Passifloraceae) em mata semidecídua ${ }^{1}$
}

\author{
CRISTIANA KOSCHNITZKE² e MARLIES SAZIMA²
}

(recebido em 07/02/96; aceito em 04/12/96)

\begin{abstract}
ABSTRATCT - (Floral biology of five species of Passiflora L. (Passifloraceae)in a semideciduous forest). A comparative study of floral biology of five Passiflora species was carried out in the region of Campinas, São Paulo, southeastern Brazil. Passiflora alata, $P$. amethystina and $P$. miersii have purple to violet flowers and variegated filamentose corona. Their flowers open early in the morning and last about 12 hours, emit sweet odour, are allogamous and their main pollinators are large bees. Passiflora amethystina and $P$. miersii have similar floral morphology, differing from $P$. alata by a row of free filaments on the edge of the operculum. The operculum in $P$. alata is horizontally curved and denticulate at the margin. These differences in the operculum require a characterist behaviour from bees during their visits. Passiflora suberosa has green-yellowish flowers and a plicate operculum. Its flowers open at dawn and no odour is perceptible. The flowers are self-compatible and their main pollinators are wasps. Passiflora capsularis has white flowers and a plicate operculum. Its flowers are nocturnal, emit sweet odour, are self-compatible and possibly are pollinated by moths. The plicate operculum of these two latter species allows easy access to nectar by the visitors.
\end{abstract}

RESUMO - (Biologia floral de cinco espécies de Passiflora L. (Passifloraceae) em mata semidecídua). O estudo da biologia floral de cinco espécies de Passiflora foi feito em uma mata de planalto em Campinas, São Paulo. Passiflora alata, $P$. amethystina e $P$. miersii apresentam flores de cor púrpura a violeta e corona variegada. As flores são diurnas, perfumadas, autoincompatíveis e polinizadas por abelhas de grande porte. Passiflora amethystina e P. miersii diferem de P. alata por apresentarem filamentos livres no opérculo, que em $P$. alata é horizontal e denticulado. Estas diferenças no opérculo promovem comportamentos característicos das abelhas durante as visitas. Passiflora suberosa possui flores verde-amareladas e opérculo plicado. As flores são diurnas, inodoras, autocompatíveis e polinizadas por vespas. Em P. capsularis as flores são brancas e o opérculo é plicado. As flores são noturnas, perfumadas, autocompatíveis e possivelmente polinizadas por mariposas. O opérculo plicado das duas últimas espécies permite que os visitantes tenham fácil acesso ao néctar.

Key words - Passiflora, floral biology, bee, wasp and moth pollination

\section{Introdução}

A família Passifloraceae é nativa dos trópicos e subtrópicos. No Brasil ocorrem quatro gêneros: Mitostemma, Dilkea, Tetrastylis e Passiflora (Cervi 1986), sendo este último o maior deles, com cerca de 200 espécies (Semir \& Brown 1975).

Knuth (1904), baseando-se na diversidade da estrutura floral das Passiflora, supôs que os polinizadores também fossem diversificados. Até aquela época, era conhecida a polinização de Passiflora por abelhas e beija-flores (Knuth 1904). Estudos realizados sobre a biologia floral e polinização de diversas espécies de Passiflora constataram a predominância de melitofilia e de ornitofilia neste gênero (Janzen 1968, Snow 1982, Gottsberger et al. 1988, May \& Spears 1988, Sazima $\&$ Sazima 1989), sendo registrada somente uma espécie quiropterófila (Sazima \& Sazima 1978).

1. Parte da Dissertação de mestrado de C. Koschnitzke.

2. Departamento de Botânica, Instituto de Biologia, Universidade Estadual de Campinas, Caixa Postal 6109, 13083-970 Campinas, SP, Brazil.
É apresentado aqui um estudo sobre a biologia floral de Passiflora alata Dryander, P. amethystina Mikan, P. capsularis L., P. miersii Mart. e P. suberosa L., simpátricas em mata semidecídua. São aqui discutidas as relações entre a morfologia externa da flor, sua biologia e seus visitantes.

\section{Material e métodos}

As cinco espécies foram estudadas na Reserva Municipal de Santa Genebra, um remanescente de mata semidecídua de

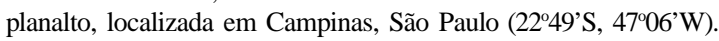
O clima na área caracteriza-se por uma estação chuvosa e quente (outubro a março) e outra seca e fria (abril a setembro). Passiflora miersii e P. suberosa foram estudadas entre março de 1990 a junho de 1992, as demais espécies, de dezembro de 1991 a junho de 1992.

As características morfológicas das flores foram examinadas a partir de material fresco e/ou fixado em álcool 70\%. Também foi registrada a presença de osmóforos (Vogel 1983), a concentração de açúcares no néctar com auxílio de refratômetro, bem como a receptividade do estigma (Zeisler 1938). As cores das flores foram determinadas com auxílio do guia de cores de Kornerup \& Wanscher (1963). No campo foram registradas as características florais durante as diversas fases da antese. Para verificar o sistema reprodutivo foram realizados tratamentos de polinização manual, segundo Radford et al. (1974). Em Passiflora miersii e P. suberosa foram feitos tratamentos de autopolinização, 
polinização cruzada e controle, em $P$. amethystina e $P$. capsularis foram realizados apenas autopolinizações e em $P$. alata não foram feitos tratamentos. Também foram registrados os visitantes, seu comportamento nas flores e a freqüência de suas visitas durante observações diurnas e noturnas. Fotografias foram feitas para análise de comportamento dos visitantes. Exsicatas das plantas estão depositadas no Herbário do Departamento de Botânica da Universidade Estadual de Campinas (UEC 27271-27274, 28709).

\section{Resultados}

As espécies de Passiflora estudadas são trepadeiras que crescem na borda da mata ou em áreas abertas. Suas flores estão dispostas horizontalmente ou levemente inclinadas em relação ao solo, com exceção de $P$. alata cujas flores são pendentes.

Suas flores são diclamídeas, com exceção de $P$. suberosa que não possui pétalas. O cálice é gamossépalo na base, onde está localizada a câmara nectarífera, coberta pelo opérculo e limitada internamente pelo límen (figuras 1-5). $\mathrm{O}$ opérculo e o límen estão em contato, fechando a câmara nectarífera. A corona é constituída por uma ou várias séries de filamentos radiais. Em geral, possuem três estiletes mas, principalmente em $P$. suberosa às vezes podem ser quatro ou cinco. $\mathrm{O}$ tamanho das flores é distinto para cada espécie, sendo $P$. alata a maior e $P$. suberosa a menor (tabela 1 ). Os períodos de floração apresentam duração variada, ocorrendo sobreposição em algumas espécies (tabela 1).

A antese caracteriza-se por expansão lenta dos elementos florais. Inicialmente ocorre a deflexão dos filetes e após certo período a dos estiletes. Esta seqüência do posicionamento das anteras e dos estigmas confere às espécies estudadas um período de protandria. A abertura das flores ocorre principalmente no período da manhã (tabela 1) e permanecem abertas cerca de 12 horas.

As flores são perfumadas, com exceção das de $P$. suberosa que não apresentam odor perceptível. Os osmóforos ocorrem na parte interna das sépalas, pétalas e filamentos da corona e do opérculo. O néctar é produzido desde o início da antese, sendo o principal recurso procurado pelos polinizadores. A concentração de açúcares no néctar difere nas espécies, sendo mais elevada em $P$. alata, $P$. amethystina, $e P$. miersii, e mais baixa em $P$. capsularis e $P$. suberosa (tabela 1).

Os resultados dos tratamentos de polinização em Passiflora amethystina, $P$. capsularis, $P$. miersii e P. suberosa constam na tabela 2. Passiflora alata é autoincompatível segundo I.G. Varassin (comunicação pessoal).

A seguir são apresentadas algumas características particulares a cada espécie.

\section{Passiflora alata}

As flores são vermelho-arroxeadas, com os filamentos longos da corona listrados de lilás a violeta, intercalados com branco. $\mathrm{O}$ opérculo é branco com anel avermelhado em sua porção mediana, sendo denticulado na margem. $\mathrm{O}$ androginóforo possui várias saliências dispostas em anel logo acima do límen, sendo mais alargado nesta região (figura 1). O límen é cupuliforme com margem engrossada, por baixo da qual se encaixa a margem do opérculo (figura 1). Durante a antese, esta espécie mantém as anteras e os estigmas dirigidos para o exterior da flor, paralelos à corona (figura 1). Somente abelhas foram observadas visitando as flores (tabela 3). Estas pousam nos filamentos externos da corona, caminham pela parte interna dos filamentos até o opérculo e, com a fronte encostada no anel de saliências do androginóforo, deslocam-no ligeiramente para o lado oposto. Com este deslocamento, abre-se um pequeno espaço entre o androginóforo e o opérculo, por onde a abelha introduz a glossa para alcançar o néctar. Epicharis flava, Xylocopa brasilianorum e Acanthopus

Tabela 1. Período de floração e características florais de cinco espécies de Passiflora da Reserva Municipal de Santa Genebra, Campinas.

\begin{tabular}{lccccc}
\hline \multicolumn{1}{c}{ Características } & P. alata & P. amethystina & P. capsularis & P. miersii & P. suberosa \\
\hline Floração (meses) & jan-jun & abr-jun & out-mai & out-abr & jan-dez \\
Abertura (horas) & $5: 00-6: 00$ & $8: 30-9: 00$ & $0: 30-1: 00$ & $7: 30-8: 00$ & $6: 00-7: 30$ \\
Diâmetro da flor $(\bar{x} \mathrm{~mm})$ & 100 & 45 & 30 & 50 & 15 \\
Concentração do néctar $(\overline{\mathrm{x}} \%)$ & 31 & 41 & 27 & 35 & 25 \\
\hline
\end{tabular}


exellens são de grandes dimensões e contactam as anteras e os estigmas com o tórax, tanto ao entrarem como ao saírem da flor. Centris labrosa e Centris sp., de dimensões médias, não contactam os órgãos reprodutivos. Augochlora sp. pousa diretamente sobre as anteras para coletar pólen, raramente contactando os estigmas.

\section{Passiflora amethystina}

Suas flores são lilás-claro, com os filamentos longos da corona violeta-claro a violeta-escuro e filamentos curtos violeta-escuro. Os filamentos do opérculo justapostos ao androginóforo, são violetaescuro e as extremidades são esbranquiçadas. Na parte interna do opérculo há uma membrana fina, branca, sanfonada com sulco mediano anular, que se encaixa na extremidade do límen (figura 2). Abelhas foram os únicos visitantes registrados nas flores de $P$. amethystina (tabela 3). Em suas visitas, Xylocopa brasilianorum apresentou comportamento semelhante ao descrito para as abelhas em $P$. miersii. Esta abelha possui dimensões adequadas para contactar os órgãos reprodutivos da flor durante as visitas, ao passo que Centris sp., de porte médio, não os contacta. Eulaema nigrita (macho) raspa os filamentos centrais mais curtos da corona, coletando substâncias odoríferas. Nesta ocasião, não contacta os orgãos reprodutivos da flor.

\section{Passiflora capsularis}

As flores são inteiramente brancas. O opérculo é plicado, translúcido e densamente pubérulo na margem. O límen é de consistência esponjosa, pubérulo e alargado no ápice, com sulcos perpendiculares à câmara nectarífera. A abertura do botão nesta espécie difere das demais, pois as sépalas começam a se abrir pela base, dando um aspecto estufado ao botão. A duração da deflexão dos elementos reprodutivos é de quatro a cinco horas. As anteras e os estigmas se deslocam menos do que nas outras espécies estudadas, permanecendo ambos dirigidos para o exterior da flor mas paralelos à corona, além disso, os estigmas posicionam-se acima das anteras (figura 3). Durante as observações noturnas não foram registrados visitantes. Em várias ocasiões, ao iniciar o período de observações ao amanhecer, foram encontradas escamas de asas de mariposas aderidas aos estigmas de várias flores desta Passiflora. Foram também registradas abelhas
Halictidae retirando pólen das anteras no período da manhã. Apesar de ser autocompatível, $P$. capsularis não apresenta autopolinização espontânea.

\section{Passiflora miersii}

As flores são brancas, com os filamentos externos da corona variegados de púrpura e branco e os filamentos mais internos violeta-escuro. $\mathrm{O}$ opérculo possui filamentos longos justapostos ao androginóforo, de cor violeta-escuro e extremidades esbranquiçadas. A extremidade do límen é ondulada e curvada em direção ao opérculo (figura 4). Os visitantes registrados nas flores foram abelhas (tabela 3). As duas espécies de Xylocopa, bem como Epicharis flava e Eulaema nigrita, aproximam-se da flor em vôo direto, pairam defronte e pousam sobre a corona, com a cabeça próxima ao androginóforo (figura 6). A seguir, afastam os filamentos do opérculo com auxílio do primeiro par de pernas, tendo assim acesso à câmara nectarífera. Nesta posição as abelhas contactam os órgãos reprodutivos da flor com o dorso do tórax (figura 6).

\section{Passiflora suberosa}

Apresenta flores amarelo-esverdeadas, com os filamentos curtos magenta. $\mathrm{O}$ opérculo é uma membrana plicada, branca com listras magenta. O límen é branco, com margem fimbriada. A câmara nectarífera é rasa e de fácil acesso (figura 5). A deflexão dos elementos reprodutivos dura quatro a cinco horas. As anteras só se tornam deiscentes uma hora após a abertura da flor. As flores foram visitadas por vespas, abelhas de pequeno porte e formigas (tabela 3). De modo geral, as flores foram pouco visitadas. As vespas realizam visitas rápidas e são pouco freqüentes. Durante a tomada de néctar, contactam os órgãos reprodutivos com a cabeça e, ao se deslocarem sobre a corona, podem contactálos também com a parte lateral do tórax (figura 7). Plebeia droryana e Augochlorella michaelis coletam pólen, podendo contactar os estigmas quando passam de uma antera para outra, promovendo autopolinização. As formigas não apresentam dimensões adequadas para contactar os órgãos reprodutivos durante as visitas à flor. Autopolinização espontânea pode ocorrer durante o período em que os estigmas estão abaixo do nível das anteras. 


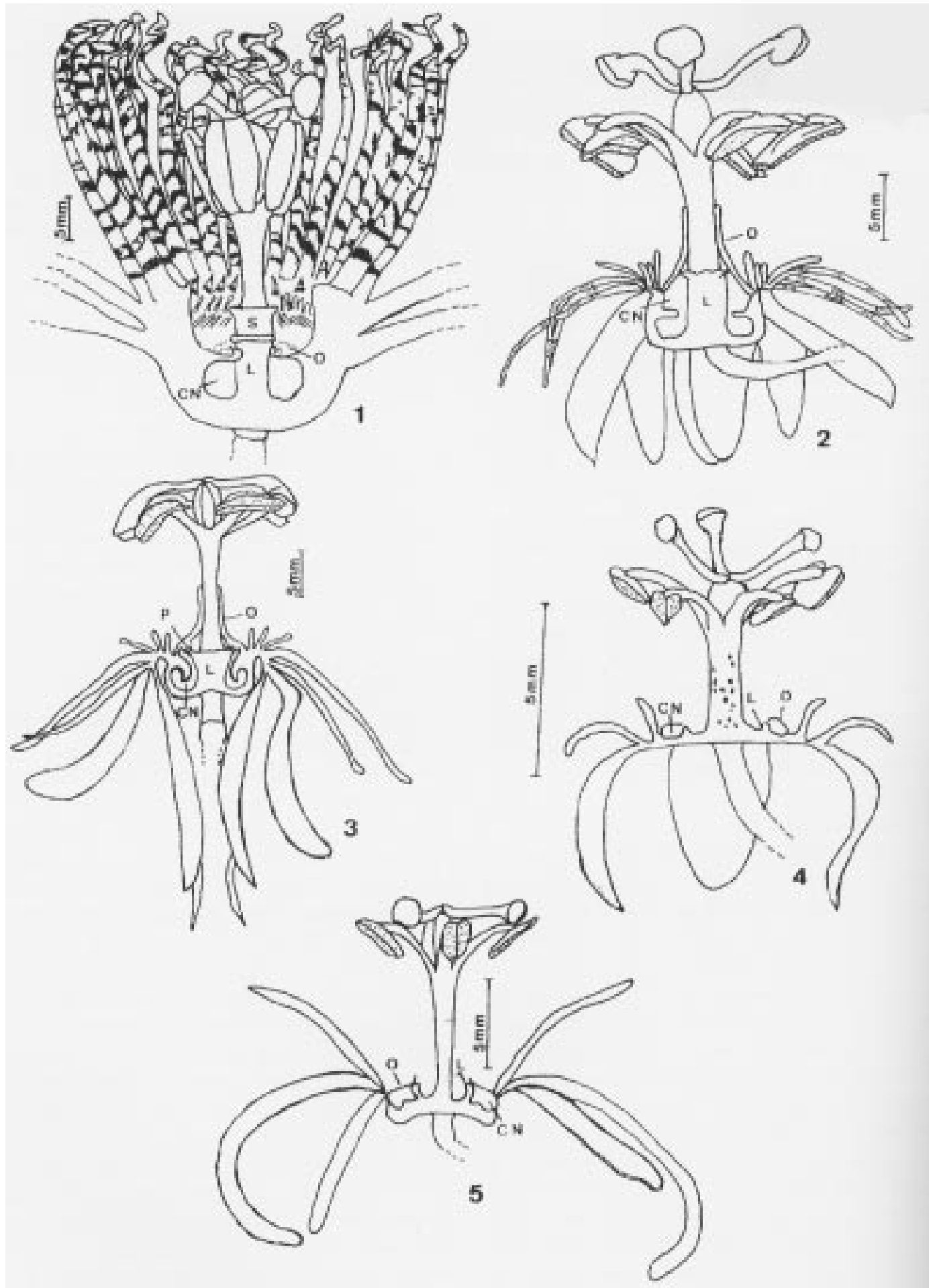

Figuras 1-5. Representação esquemática das flores de Passiflora, mostrando a base da corola em corte longitudinal. 1. P. alata; 2. P amethystina; 3. P. capsularis; 4. P. miersii; 5. P. suberosa. $\mathrm{CN}$ - câmara nectarífera, L - límen, $\mathrm{O}$ - opérculo, S - saliências e P - projeções. 
Tabela 2. Porcentagem de formação de frutos para tratamento de polinização cruzada (PC), autopolinização (AP) e condições naturais (CN) em quatro espécies de Passiflora da Reserva Municipal de Santa Genebra, Campinas.

\begin{tabular}{ccccc}
\hline Tratamento & $P$. amethystina & P. capsularis & P. miersii & P. suberosa \\
\hline PC & - & - & $60(\mathrm{n}=5)$ & $91(\mathrm{n}=12)$ \\
AP & $0(\mathrm{n}=2)$ & $100(\mathrm{n}=3)$ & $0(\mathrm{n}=15)$ & $74(\mathrm{n}=31)$ \\
CN & - & - & $51(\mathrm{n}=27)$ & $52(\mathrm{n}=17)$ \\
ISI* & - & - & 0 & 0,81 \\
\hline
\end{tabular}

*ISI - índice de autoincompatibilidade

Tabela 3 - Insetos visitantes, recurso floral procurado e atividade na flor de quatro espécies de Passiflora da Reserva Municipal de Santa Genebra. (N - Néctar, P - Pólen, O - substâncias odoríferas, pa - autopolinizador, po - polinizador, pi - pilhador)

\begin{tabular}{|c|c|c|c|c|}
\hline Visitantes & P. alata & P. amethystina & P. miersii & P. suberosa \\
\hline \multicolumn{5}{|l|}{ Abelhas } \\
\hline Centris labrosa & N, pi & & & \\
\hline Centris sp. & $\mathrm{N}$, pi & $\mathrm{N}$, pi & & \\
\hline Epicharis flava & $\mathrm{N}$, po & & $\mathrm{N}$, po & \\
\hline Xylocopa brasilianorum & $\mathrm{N}$, po & $\mathrm{N}$, po & $\mathrm{N}$, po & \\
\hline Xylocopa suspecta & & & $\mathrm{N}$, po & \\
\hline Eulaema nigrita & & $\mathrm{O}$ & $\mathrm{N}$, po & \\
\hline Plebeia droryana & & & $\mathrm{N}, \mathrm{pi}$ & $\mathrm{N}, \mathrm{P}, \mathrm{pa}$ \\
\hline Trigona spinipes & & & $\mathrm{N}, \mathrm{P}, \mathrm{pi}$ & \\
\hline Augochlorella michaelis & & & & $\mathrm{N}, \mathrm{P}, \mathrm{pa}$ \\
\hline Augochlora sp & $\mathrm{P}, \mathrm{pi}$ & & & \\
\hline Acanthopus exellens & $\mathrm{N}$, po & & & \\
\hline \multicolumn{5}{|l|}{ Vespas } \\
\hline Mischocyttarus interjectus & & & & $\mathrm{N}$, po \\
\hline Eumenidae sp. 1 & & & & $\mathrm{~N}$, po \\
\hline \multicolumn{5}{|l|}{ Formigas } \\
\hline Camponotus crassus & & & & $\mathrm{N}, \mathrm{pi}$ \\
\hline Iridomyrmex sp. & & & & $\mathrm{N}$, pi \\
\hline Pseudomyrmex sp. & & & & $\mathrm{N}, \mathrm{pi}$ \\
\hline Pheidole sp. & & & & $\mathrm{N}, \mathrm{pi}$ \\
\hline
\end{tabular}

\section{Discussão}

Com base na morfologia floral, principalmente pelos atributos do opérculo, estas espécies podem ser reunidas em dois grupos, um formado por Passiflora alata, $P$. amethystina e $P$. miersii, que possuem opérculo filamentoso ou denticulado e outro por $P$. capsularis e P. suberosa, que apresentam o opérculo plicado. No primeiro grupo, estas estruturas florais tornam o néctar acessível apenas a determinados visitantes, porque se encaixam de modo que somente um visitante com aparelho bucal longo e resistente, como abelhas de grande porte, consegue afastar o opérculo e ter acesso à câmara nectarífera. O opérculo e o límen são estruturas que protegem o néctar (Endress 1994) sendo consideradas como especializações a determinados polinizadores (Heinrich \& Raven 1972, Proctor \& Yeo 1975, Faegri \& van der Pijl 1980). No segundo grupo, o opérculo plicado permite o acesso ao néctar a visitantes menos especializados, com aparelho bucal curto, como as vespas e formigas.

Diversas características das flores de $P$. alata, $P$. amethystina e P. miersii, estão de acordo com a síndrome de melitofilia descrita por Faegri \& van der Pijl (1980). Apesar de não haver síndrome bem 


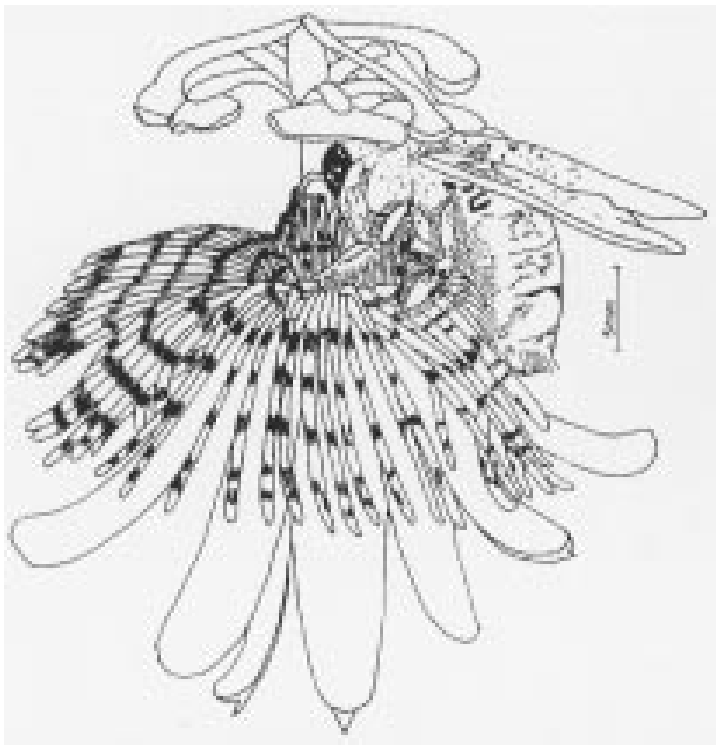

Figura 6. Esquema da flor de Passiflora miersii sendo visitada por Xylocopa brasilianorum. A abelha contacta as anteras e os estigmas com o dorso do tórax.

definida para flores polinizadas por vespas, alguns atributos de $P$. suberosa, tais como flores pequenas e rasas, com cores opacas e néctar de fácil acesso, correspondem aos descritos para flores polinizadas por vespas em Faegri \& van der Pijl (1980) e Heithaus (1979). As características florais de $P$. capsularis correspondem à síndrome de falenofilia (Faegri \& van der Pijl 1980). Um dos atributos mais evidentes seria o guia de língua, formado pelos sulcos do límen perpendiculares à câmara nectarífera, que acompanham as dobras do opérculo. Estes guias são estruturas especializadas, encontradas geralmente em flores polinizadas por lepidópteros (Faegri \& van der Pijl 1980).

A antese das flores no início da manhã não é regra geral para as espécies melitófilas de Passiflora, pois as flores de P. incarnata (May \& Spears 1988) e P. edulis (Sazima \& Sazima 1989) abrem entre 11:00 e 14:00 h. Sazima \& Sazima (1989) sugerem que este período de abertura seja uma estratégia para evitar a sobreposição de polinizadores, com outras espécies de Passiflora sincronopátricas cujas flores abrem ao amanhecer. O fato das flores de $P$. capsularis permanecerem abertas até às 13:00 h, permite, à semelhança do que ocorre em P. mucronata (Sazima \& Sazima 1978), a polinização também por insetos

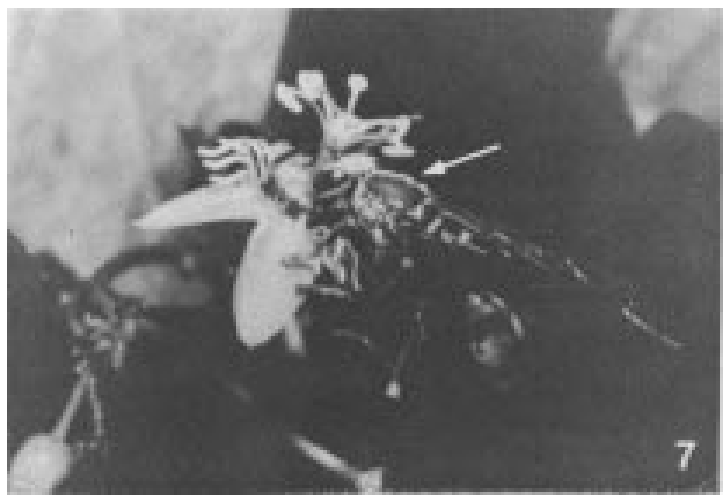

Figura 7. Flor de Passiflora suberosa sendo visitada pela vespa Mischocyttarus interjectus. Há pólen depositado sobre a cabeça e as partes laterais do tórax da vespa.

diurnos, aspecto que não ocorre em outras passifloráceas de antese noturna, como P. galbana (C. Koschnitzke, observação pessoal) e Tetrastylis ovalis (Buzato \& Franco 1992), cujas flores fecham ao amanhecer. Apesar de seus horários de abertura serem diversos, as espécies estudadas apresentam duração média de 12 horas, aspecto que parece ser uma tendência do gênero Passiflora (Endress 1994).

A lenta expansão dos elementos florais durante a antese, nas espécies estudadas, é semelhante ao que ocorre em P. vitifolia (Snow 1982) e P. speciosa (M.R. Sigrist, comunicação pessoal). Em outras espécies, como P. mucronata (Sazima \& Sazima 1978), a expansão ocorre em quinze segundos e, em $P$. foetida (Gottsberger et al. 1988), em dois ou três minutos. Também não há padrão na duração da deflexão dos estiletes, que pode variar de dez minutos, como em P. foetida (Janzen 1968, Gottsberger et al. 1988) até quatro a cinco horas, como em $P$. suberosa e $P$. capsularis. As diferenças na duração dos movimentos e na disposição final das anteras e estigmas, em relação às outras peças florais, poderiam estar relacionadas ao comportamento de seus polinizadores (Janzen 1968, Semir \& Brown 1975). O movimento dos estiletes, em particular, que resulta numa posição adequada dos estigmas para contactar os polinizadores somente em determinado período após o início da antese, confere às flores um período de protandria (Endress 1994) sendo interpretado como um mecanismo que favorece a polinização cruzada (Janzen 1968). 
Em P. alata, $P$. amethystina e P. miersii, devido ao colorido contrastante e à presença de osmóforos nos filamentos, a corona é considerada como elemento atrativo, sendo um guia visual e olfativo (Faegri \& van der Pijl 1980, Endress 1994).

As concentrações de açúcares no néctar das flores de $P$. alata, $P$. amethystina e $P$. miersii correspondem às de outras espécies melitófilas (Percival 1965, Pyke \& Waser 1981), a de Passiflora suberosa concorda com a amplitude de concentração para flores polinizadas por vespas (Percival 1965) e a de $P$. capsularis está mais próxima da conhecida para flores polinizadas por borboletas do que por mariposas esfingídeas (Pyke \& Waser 1981).

Passiflora alata, P. amethystina e P. miersii são autoincompatíveis, como a maioria das espécies de Passiflora que apresentam flores conspícuas (Janzen 1968, Semir \& Brown 1975, Endress 1994). $P$. capsularis e $P$. suberosa são autocompatíveis à semelhança de $P$. eglandurosa (McDougal 1988) e P. rutilans (Lewis 1979, Endress 1994), que apresentam em comum flores pequenas e inconspícuas. A quebra da autoincompatibilidade em muitas espécies leva à autogamia facultativa (Stebbins 1970), o que pode estar associado ao fato de serem ruderais e de não possuírem um polinizador freqüente (Cruden 1977).

Espécies de Xylocopa, polinizadoras de P. alata, $P$. amethystina e $P$. miersii, apresentam vários atributos que favorecem a polinização cruzada, tais como dimensões compatíveis com a morfologia da flor, alta freqüência de visitas, padrão de forrageamento em "linhas de captura" (Janzen 1971, Waddington 1983) e comportamento de não pousar em flores recentemente visitadas (van der Pijl 1954, Frankie \& Vinson 1977, Waddington 1983). Além disso, são abelhas muito versáteis, capazes de explorar diferentes tipos morfológicos de flores, como é o caso destas espécies de Passiflora e de várias outras citadas por van der Pijl (1954). Este gênero de abelhas possui importância fundamental na polinização de Passiflora (Endress 1994). As demais abelhas de grande porte também tem acesso fácil ao néctar (Endress 1994), e embora pouco freqüentes, são efetivas na polinização destas espécies de Passiflora

As vespas são polinizadoras principais de $P$. suberosa apesar da baixa freqüência de visitas. Embora esta Passiflora seja autocompatível, as vespas garantem a polinização cruzada, fato que reduz a perda de variabilidade genética que a reprodução autogâmica poderia causar (Richards 1986).

A presença de escamas de mariposas aderidas aos estigmas das flores de $P$. capsularis, aliada às características florais: antese noturna, odor suave e agradável, flores brancas e guias de língua, fortalece a sugestão de falenofilia para esta espécie de Passiflora.

$O$ registro da polinização por vespas em $P$. suberosa e por mariposas em $P$. capsularis é inédito para o gênero. Sugerimos que especialmente a falenofilia, seja pouco representada no gênero, uma vez que predominam espécies polinizadas por abelhas e beija-flores (Endress 1994).

Agradecimentos- A João M. F. Camargo, Sulene N. Shima e Inara R. Leal pela identificação dos insetos; a George J. Shepherd pela revisão do abstract; a M. Rosângela Sigrist pela foto, a lvan Sazima e Ana Odete S. Vieira pela leitura do manuscrito; ao $\mathrm{CNPq}$ pelo auxílio financeiro.

\section{Referências bibliográficas}

BUZATO, S. \& FRANCO, A.L.M. 1992. Tetrastylis ovalis: a second case of bat-pollinated passionflower (Passifloraceae). Pl. Syst. Evol. 181:261-267.

CERVI, A.C. 1986. Passifloraceae. In Flora do Estado de Goiás, vol. 7, (J.A. Rizzo, ed.), Goiânia, p.1-44.

CRUDEN, R.W. 1977. Pollen-ovules ratios: a conservation indicator of breeding systems in flowering plants. Evolution 31:32-46.

ENDRESS, P.K. 1994. Diversity and evolutionary biology of tropical flowers. Cambridge University Press, Cambridge.

FAEGRI, K. \& VAN DER PIJL, L. 1980. The principles of pollination ecology. Pergamon Press, New York.

FRANKIE, G.W. \& VINSON, S.B. 1977. Scent marking of passion flowers in Texas by females of Xylocopa virginica texana (Hymenoptera: Anthophoridae). J. Kansas Entomol. Soc. 50:613-625.

GOTTSBERGER, G., CAMARGO, J.M.F. \& SILBERBAUERGOTTSBERGER, I. 1988. A bee-pollinated tropical community: the beach dune vegetation of Ilha de São Luiz, Maranhão, Brazil. Bot. Jb. Syst. 109:469-500.

HEINRICH, B. \& RAVEN, P.H. 1972. Energetics and pollination ecology. Science 176:597-602.

HEITHAUS, E.R. 1979. Community structure of neotropical flower visiting bees and wasps: diversity and phenology. Ecology 60:190-602.

JANZEN, D.H. 1968. Reproductive behaviour in the Passifloraceae and some of its pollinators in the Central America. Behaviour 32:33-48.

JANZEN, D.H. 1971. Euglossine bees as long-distance pollinators of tropical plants. Science 171:203-205.

KORNERUP, A. \& WANSCHER, J.H. 1963. Taschenlexikon der Farben. Sadolin \& Holmblad A/S, Kopenhagen.

KNUTH, P. 1904. Handbuch der Blütenbiologie III. Engelmann, Leipzig. 
LEWIS, D. 1979. Sexual incompatibility in plants. Edward Arnold, London.

MAY, P.G. \& SPEARS Jr., E.E. 1988. Andromonoecy and variation in phenotypic gender of Passiflora incarnata (Passifloraceae). Am. J. Bot. 75:1830-1841.

McDOUGAL, J.M. 1988. Passiflora eglandulosa, a new species in section Cieca (Medikus) DC. formely included with $P$. trinifolia Masters. Ann. Mo. Bot. Gard. 75:1658-1662.

PERCIVAL, M.S. 1965. Floral biology. Pergamon Press, London.

PROCTOR, M. \& YEO, P. 1975. The pollination of flowers. W. Collins Sons \& Co. Ltd., London.

PYKE, G.H. \& WASER, N.M. 1981. The production of dilute nectars by hummingbird and honeyeater flowers. Biotropica 13:260-270.

RADFORD, A.E., DICKSON, W.C., MASSEY, J.R. \& BELL, C.R. 1974. Vascular plant systematics. Harper \& Row, New York.

RICHARDS, A.J. 1986. Plant breeding systems. George Allen \& Unwin, London.

SAZIMA, I. \& SAZIMA, M. 1989. Mamangavas e irapuás (Hymenoptera, Apoidea): visitas, interações e consequências para a polinização do maracujá (Passifloraceae). Revta. Bras. Ent. 33:108-118.

SAZIMA, M. \& SAZIMA, I. 1978. Bat pollination of the passion flower. Passiflora mucronata in southeastern Brazil. Biotropica 10:100-109.
SEMIR, J. \& BROWN Jr., K.S. 1975. Maracujá: a flor da paixão. Revta. Geog. Univ. 2:40-47.

SNOW, A.A. 1982. Pollination intensity and potencial seed set in Passiflora vitifolia. Oecologia 55:231-237.

STEBBINS, G.L. 1970. Adaptative radiation of reproductive characteristics in Angiosperms, I Pollination mechanisms. Ann. Rev. Ecol. Syst., 1:307-326.

VAN DER PIJL, L. 1954. Xylocopa and flowers in the tropics I, III. Proc. Sec. Sc. 57:413-423.

VOGEL, S. 1983. Ecophysiology of zoophylic pollination. In Physiological plant ecology III (O.L. Lange, P.S. Nobel, C.B. Osmond \& H. Ziegler, eds.). SpringerVerlag, Berlin, p.560-611.

WADDINGTON, K.D. 1983. Foraging behaviour of pollinators. In Pollination biology, (L. Real, ed.) Academic Press. California, p.213-235.

WYATT, R. 1983. Pollinator-plant interactions and the evolution of breeding systems. In Pollinations biology, (L. Real, ed.). Academic Press, California, p.51-86.

ZEISLER, M. 1938. Über die Abgrenzung der eigentlichen Narbenfläche mit Hilfe von Reaktionen. Beih. Bot. Zbl. 58:308-318. 